\title{
Why Insurers Fail: The Dynamics of Property and Casualty Insurance Insolvency in Canada
}

\author{
Darrell Leadbetter ${ }^{\mathrm{a}}$ and Suela Dibra ${ }^{\mathrm{b}}$ \\ ${ }^{a}$ Property \& Casualty Insurance Compensation Corporation (PACICC), Research, 20 Richmond St. East, \\ Suite 210, Toronto, ON, Canada M5C 2R9. \\ E-mail: dleadbetter@pacicc.ca \\ ${ }^{\mathrm{b}}$ Insurance Bureau of Canada, Policy, 777 Bay Street, Suite 2400, PO Box 121, Toronto, ON, Canada M5G 2 C8. \\ E-mail: sdibra@ibc.ca
}

We analyze the involuntary exit of 35 property and casualty insurance companies from the Canadian insurance market over the 1960-2005 period, and consistent with other jurisdictions, find evidence that inadequate pricing and deficient loss reserves are the leading cause of insurer insolvency. Overall, we find that the operating environment generally provides the catalyst for insolvency, either through turbulent financial markets or reduced profitability in the industry, but most causes of involuntary exit can however be linked back to three sources within an institution: the quality and experience of governance/management, internal operational processes and risk appetite. Further, other than inadequate pricing, our results, when compared with the few studies in various jurisdictions, indicate there are few universal causes of involuntary exit across jurisdictions, and hence supervisory approaches to insurer insolvency should be flexible and adaptable to the environment.

The Geneva Papers (2008) 33, 464-488. doi:10.1057/gpp.2008.14

Keywords: insurer insolvency; financial distress; insurance regulation; guarantee funds

We are never more in danger than when we think ourselves most secure.

William Cowper (1731-1800)

\section{Introduction}

The involuntary exit of insurance companies is not random or completely unpredictable. While some causes of involuntary exit have remained consistent, others have exhibited changing patterns over time. Improvements in solvency supervision and the winding-up of insurance companies can be achieved through better understanding of the causes of insolvency. Within this context, we conducted the first comprehensive study of the causes of involuntary market exit in the property and casualty $(\mathrm{P} \& \mathrm{C})$ insurance industry in Canada. This study identifies some of the main characteristics of the 35 involuntary market exits that occurred during the 45-year period between 1960 and 2005.

The likelihood of an insolvency assessment by the guarantee fund protecting policyholders from insolvency on the $\mathrm{P} \& \mathrm{C}$ insurance industry in any given year is significant (insurers were assessed in 12 out of 17 years between 1990 and 2007). While 
the frequency has been high, the size of those assessments has been low, an average of 0.03 percent of industry premium, but it has been increasing at nearly three times the rate of inflation.

For consumers, insurance is a key risk management strategy, so it is important to minimize the disruption of an insurance company insolvency. Insurer insolvency exposes claimants and policyholders to an unexpected financial loss and may potentially be associated with considerable personal and economic cost. Further, the insurance industry is built on policyholder confidence that insurance contracts will be fulfilled and eligible claims paid. Insurer insolvency may therefore lead to reduced confidence in financial institutions.

Insolvency is a term that in various contexts can have different meanings. We define an insolvency as an involuntary exit from the market precipitated by a winding-up order issued by the appropriate supervisory authority. Insurance companies may be wound-up when they become an insolvency risk or a liquidity risk. An insolvency risk occurs when assets become insufficient for an insurance company to meet its contractual and other financial obligations. ${ }^{1}$

An insurer experiences a liquidity risk when it has sufficient assets to cover its obligations but there is a high level of risk that those assets could disappear. Historically all liquidity risks have been branch companies, which are run out of their foreign home office. Only the Office of the Superintendent of Financial Institutions (OSFI) may supervise branch companies. Troubled insurance companies that exited the market through mergers (so-called "near misses") or run-off are not included in this analysis. An estimated 42 companies, with approximately $\$ 1$ billion in liabilities, are in run-off in Canada. BarNiv and Hathorn ${ }^{2}$ found that distressed mergers comprised 20-46 percent of merged insurers.

Throughout this paper, the term "involuntary market exit" is used encompassing both insolvency and liquidity risks. The particular contribution of this paper is to add to the understanding of involuntary exit in the Canadian P\&C industry. In conjunction with the previous literature from other jurisdictions, the results may help supervisory authorities and policyholder protection funds better understand and monitor insolvency risks.

\section{A historical overview of insurer insolvency in Canada}

Foreign-owned insurance companies are important participants in Canada's P\&C insurance market, accounting for approximately two-thirds of net premiums earned. For consumers, competition, access to foreign capital and the diversification of risk generate benefits in the form of lower prices, innovation and financially sound companies. However, it does mean that on some occasions, when a foreign parent exits

\footnotetext{
${ }^{1}$ Given the complex and long-term nature on many lines of business, even accurately measuring the assets or liabilities of an insurance company may be challenging. Therefore, an insurance company may be deemed insolvent if the estimated assets are insufficient to meet the company's obligations with a very high level of confidence (e.g. 95-99 percent).

${ }^{2}$ BarNiv and Hathorn (1997).
} 
the market involuntarily, the Canadian operations may also fail or in the case of branches present a liquidity risk to Canadian policyholders.

It can be important to distinguish between Canadian chartered (whether foreign or Canadian owned) and branch companies. Canadian insurers fail as a result of their operation and exposure to the Canadian economic/underwriting environment while branch companies may fail because the home office company in a foreign jurisdiction has failed due to the economic/underwriting environment in a foreign jurisdiction.

Since 1960, the Canadian P\&C insurance industry encountered three waves of involuntary exits, which coincided with periods of poor profitability. Two waves of involuntary exit took place after 1990, with 57 percent of all exits since 1960 occurring in the past 15 years. In addition, there has been a shift in the nature of involuntary exits. The number of such institutions under federal supervision has declined. In addition, all but one of the institutions supervised by the federal government woundup since 1990 were liquidity risks rather than an insolvency risk, reflecting the mandate of the OSFI to protect Canadian policyholders in instances where the foreign parent insurer failed. The number of company involuntary exits supervised by provincial regulators nearly doubled from four in the 30-year period before 1990 to seven in the 15-year period after 1990.

Figure 1 shows the annual number of P\&C involuntary exits for the 45-year period from 1960 to 2005 . The first wave of involuntary exits came in the early 1980s, which coincides both with reduced profitability in the insurance industry and a recessionary period for Canadian economy. Subsequent waves of involuntary exit similarly coincided with poor profitability and a worsening insurance cycle.

\section{Literature review}

Although to our knowledge there are no theoretical models specific to insurance company survival, there are two frameworks for looking at firm survival and exit. The first framework is a dynamic equilibrium model for a competitive industry that endogenously characterizes the process for the entry and exit of individual firms. The second, a firm survival approach, estimates a firm's probability of survival based on certain firm attributes.

An example of the dynamic equilibrium model framework is that developed by Hopenhayn. ${ }^{3}$ In this framework, the industry is composed of a continuum of firms that produce a homogeneous product. The firms behave competitively by taking the output and input prices as given. The output of a firm is a function of productivity shocks, a measure of how well a firm produces the good or service. In the insurance industry for example, a shock may be an innovation in underwriting techniques (positive).

\footnotetext{
${ }^{3}$ Only a brief outline of the model is presented here. The model is fully outlined in Hopenhayn (1992). Variations of this model exist within the literature. Jovanovic (1982) pioneered innovative work on firm selection and survival and forms the basis from which Hopenhayn (1992) and others further developed.
} 


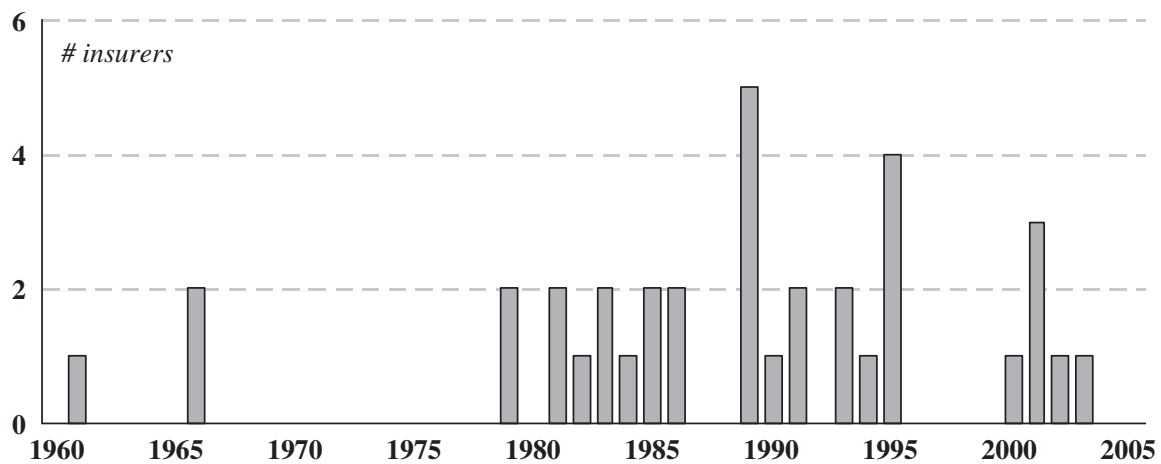

Figure 1. Involuntary market exits in Canada. Source: PACICC.

The firm pays a fixed cost when operating in the market. To enter the market, a new firm must pay an entry $\operatorname{cost} c_{e}>0$. Prior to paying this entry cost a new entrant has not yet learned its input or output prices, as these functions are not fully known prior to entry. In some regards this is analogous to an insurer which is required to meet certain capital requirements (entry costs) before becoming licensed, and which is also, without a claims history, subject to greater uncertainty in its costs.

Firm-specific shocks are the primary source of uncertainty in the model. This is analogous to the industry as a whole exhibiting predictable patterns but with heterogeneity among individual firms (e.g., in terms of claims costs). Firm turnover (voluntary and involuntary) is related to the expected discounted profits, the cost of entry and a firm's productivity. A competitive equilibrium for the industry is attained when there are no further incentives to enter or exit the market. In a competitive equilibrium setting, prices are market clearing and the exit rule is chosen optimally.

The model generates a number of specific predictions. Of particular interest is the effect that changes in some of the parameters of the industry have on the equilbrium. Changes in the cost of entry increase the profit that a firm must earn in order to stay in the market. Therefore, the model predicts that higher costs of entry will reduce the number of firms as lower productivity firms exit the market. In subsequent periods, the industry experiences lower firm turnover, including reduced involuntary exit. Existing firms earn higher profits and are protected from new entrants by the higher entry costs. $^{4}$

Decreasing the cost of entry, for example lowering capital requirements, has the opposite effect. More firms are able to stay in or enter the market. For consumers this means increased choice and competition. However, lower productivity firms are more vulnerable to shocks, for example adverse development or interest rate volatility. For lower costs of entry, the model predicts higher firm turnover rates as companies exit and enter the market more frequently.

\footnotetext{
${ }^{4}$ Hopenhayn (1992).
} 
Risk-based effects were not explicitly incorporated into the original discussion of the model. However, extending the model conceptually suggests that the introduction of firm-specific risk-based effects would create an environment where the cost of entry is re-established in each period and moves with the risk profile of the firm. In general, this suggests low productivity firms will either operate in low risk areas of the market or exit. Participation in higher risk areas of the market would require higher levels of productivity (expertise). Overall, turnover and involuntary exit rates are reduced. In general, the model would appear to imply that risk-based approaches to insurance supervision would act to reduce the incidence of involuntary exit.

The second framework for the study of firm survival and failure estimates a firm's probability of survival based on certain attributes. There are a number of noteworthy findings from this literature, including the role of management and age on firm survival.

Several studies, building on research by Dunne et al., ${ }^{5}$ found that diversified firms survive longer and grow faster than new entrants, but also that diversifying firms with experience in related fields perform better than less experienced entrants. Examples of this literature include Mitchell, ${ }^{6}$ Carroll et al. ${ }^{7}$ and Klepper and Simons. ${ }^{8}$

A number of studies find that a strong reservoir of support is important for firm survival. In an insurance context, this could take the form of capital or technical support from a parent company. For example, Klepper and Sleeper ${ }^{9}$ and Walsh et al. ${ }^{10}$ find that subsidiary companies survive longer than new stand-alone companies. Further, Klepper and Thompson ${ }^{11}$ demonstrate that the quality of a subsidiary's parent company is an important factor for survival. Eisenhardt and Schoonhoven ${ }^{12}$ report that firm performance is increasing with the industry experience of their management. Similarly, Thompson ${ }^{13}$ found that new entrants learn by doing, with results improving over time and that the prior experience of management is an important factor in firm survival rates.

Generally, this research literature has consistently found that:

- pre-entry experience has large and persistent effects on firm survival;

- new entrants learn by doing, with improved results over time;

- firms with more experienced managers have a higher survival rate:

- survival rate is increasing with respect to age.

These research findings concerning firm survival or involuntary market exit are drawn from the manufacturing industry, but may nevertheless offer a number of lessons for the insurance industry. In fact, those results are consistent with what we

\footnotetext{
${ }^{5}$ Dunne et al. (1988).

${ }^{6}$ Mitchell (1991).

${ }^{7}$ Carroll et al. (1996).

${ }^{8}$ Klepper and Simons (2000).

${ }^{9}$ Klepper and Sleeper (2001).

${ }^{10}$ Walsh et al. (1996).

${ }^{11}$ Klepper and Thompson (2002).

${ }^{12}$ Eisenhardt and Schoonhoven (1990).

13 Thompson (2005).
} 
find for the Canadian P\&C industry. The lessons from both the dynamic equilibrium and hazard models frameworks are complementary and add to our overall understanding of the dynamics of insolvency. In general, the dynamic equilibrium model framework highlights the effect that environmental factors have on firm entry and exit. The hazard model framework takes a stationary equilibrium and analyzes factors that move the market to a new equilibrium.

\section{Empirical analysis}

The incidence of involuntary exit has varied across time and jurisdictions. There exists a wealth of research concerning the insolvency issue in the P\&C insurance industry internationally. Typically, the studies take one of two approaches depending on data availability. Studies using financial statement data have explored the relationships between financial indicator variables and the probability of insolvency, usually using a logit approach. The other branch of studies takes a more forensic approach, usually using the more detailed confidential data available to a regulator or rating agency, breaking down the internal and external factors that contributed to each individual insolvency, and then identifying trends and common factors.

The literature utilizing the financial indicator approach is largely U.S.-based, using National Association of Insurance Commissioners' (NAIC) risk-based capital (RBC) and Financial Analysis Solvency Tools (FAST) measures. ${ }^{14}$ In general, all these studies highlighted the relatively poor predictive value of particular financial indicators, although using a variety of such indicators improved the results. One study ${ }^{15}$ found that cash flow simulation improved the capacity to correctly predict insolvency. Another ${ }^{16}$ found that private sector information as proxied by A.M. Best's financial strength rating and capital score was better than the FAST measures. Pottier and Sommer conjectured that the private sector measures incorporated qualitative data that were not captured by the purely quantitative FAST and RBC measures.

One of the most recent studies concerning the sources of $\mathrm{P} \& \mathrm{C}$ insurance involuntary exit is A.M. Best's insolvency report. ${ }^{17}$ This report examines 871 insurance companies identified as being financially impaired. The primary internal causes identified from the study were deficient loss reserves and inadequate pricing (which accounted for 37 percent of failures) and rapid growth (which accounted for an additional 22 percent of financial impairments).

The second most common cause of impairment, rapid growth, occurred most frequently during soft market conditions with weak industry profits. The study found that diminished capital strength drove insurers into aggressive expansion strategies, including business/lines where underwriting experience was lacking. Other significant causes of financial impairment identified by the A.M. Best study were fraud, overstatement of assets and catastrophe losses. It appeared that alleged fraud increased up to the early 1990s and declined afterwards as supervisory authorities

\footnotetext{
${ }^{14}$ Cummins et al. (1995, 1999); Grace et al. (1998); Pottier and Sommer (2002).

${ }^{15}$ Cummins et al. (1999).

${ }^{16}$ Pottier and Sommer (2002).

17 A.M. Best (2004).
} 
introduced a number of reporting and corporate governance reforms and enhanced their supervision of the industry. Of particular interest is A.M. Best's opinion that "... all primary causes of financial impairments in this study were related to some form of mismanagement", 18

A study by the Financial Services Authority (FSA) in the United Kingdom analyzed recent experiences of failed insurance companies across life and non-life sectors covering 15 countries of the European Union. The FSA analysis is based upon the Sharma $^{19}$ report. From 270 involuntary exits, a sample of 21 cases was selected covering each of the main risks identified by the group members (in total 50 generic risks were identified). The FSA utilized a methodology linking all risks an insurance company faces into causal chains. A detailed cause-and-effect risk map for each case study was developed. This helped identify both the relative importance of a risk and also its ultimate impact. ${ }^{20}$

The FSA study concluded that over 60 percent of the companies showed poor underwriting or reserving as a contributing factor. Second in the list is asset risk stemming from investments whose value was likely to be adversely affected by the same occurrences leading to large claims, thus exposing the firm to a "double gearing" effect. Other causes identified were management/governance, external causes and reinsurance risk. All the case studies had significant underlying management or governance issues.

There has also been research concerning involuntary exits in Asian P\&C insurance markets. Involuntary exits in most Asian insurance markets are unusual, as historically insurance supervisors in those markets have sought to prevent insurance company failures. A study by Chen and Wong ${ }^{21}$ that focuses on the insurance market in Singapore, Japan, Malaysia and Taiwan uses financial ratios to classify the insurers as financially stable and unstable. A logit model was used to detect the impact that firm-specific characteristics have on insurers' financial health. The authors found that firm size (measured by the total admitted assets), investment performance, liquidity and profitability ratios were positively related to financial health, while growth of surplus was negatively related to the insurer's financial health for Singapore. On the other hand, for all four countries included in this study, the authors found a negative correlation between combined ratio and the financial health.

Lee and Urrutia $^{22}$ found similar results when they tested the explanatory power of firm-specific characteristics on the financial impairment of insurers in the United States. While the methodologies are quite different, in particular lacking the detailed qualitative and financial data, nevertheless the findings from the Asian market study differ slightly from the A.M. Best and FSA studies. Certain factors such as premium growth appeared to have an insignificant effect on insurer financial health for the Asian market, while for the U.S. market it represented the second most important cause of involuntary exit.

\footnotetext{
18 Ibid.

${ }^{19}$ Sharma (2002).

${ }^{20}$ McDonnell (2002).

${ }^{21}$ Chen and Wong (2004).

${ }^{22}$ Lee and Urrutia (1996).
} 


\section{Methodology and data}

Most of the literature, particularly that from the United States, is based upon the statistical analysis of financial indicators and some qualitative variables characterized by dummy variables. Such approaches are helpful in understanding how much reliance may be placed on a given variable(s) and may provide insight as to which financial indicators are useful as early warning indicators. However, the wide variation of actual variables used among the aforementioned studies suggests that there may not be a given set of variables that are superior in predicting insolvency to any other set of variables.

The financial indicator approach presents a number of challenges for analyzing financial distress. First, this approach is reliant upon accounting data, and new accounting standards may be altering the explanatory power of financial ratios in predicting insolvency. Changes in accounting policies over time may result in changes in the underlying correlations with financial indicator variables, reducing their predictive value over time. Greater management discretion in some factors (e.g., the discount factor on technical provisions introduced for Canadian insurers in 2003) and unobserved differences in these choices across insurers may also influence the robustness of financial indicators over time. In Canada there have been three major accounting and several minor financial reporting changes since 1990. Second, with only 35 insolvencies over the 47-year period of study and different reporting requirements over time and during the earlier part of the study period between jurisdictions, the detail and quality of data make the use of logit or probit models more challenging.

Further, while it could be argued that financial data are proxy for the underlying causes of insolvency, such data does not necessarily improve understanding of the processes of how insurers become insolvent but rather correlates financial outcomes with insolvency. This is evidenced by the relatively low predictive value of financial indicators for insolvency. ${ }^{23}$ As a result, while financial indicators are a valuable earlywarning tool, the literature on such approaches offers limited guidance on the specific financial indicators to use or of what to look for after an initial warning. Perhaps an appropriate analogy may be that looking at financial indicators is similar to trying to determine why a ship sank by looking at wind speed, direction and the water's surface characteristics without being able to see whether there were currents, sharp rocks, mechanical or pilot error. While surface conditions are important and can place a ship in jeopardy (and occasionally cause it to sink), good pilots in good ships can usually navigate through all but the worst weather.

Given these considerations, the primary methodology of this study is a forensic approach, supplemented by simple bivariate and multivariate regression analysis of macro-environment variables on insolvency rates in order to identify whether some of the environmental or "surface" conditions were relevant factors. In effect, our results are the summary of 35 individual case studies. Nevertheless, the case study approach may suffer from the "cannot see the forest from the trees" issue. Therefore, where possible, an optimal approach would be to combine the two methodologies to develop a deeper understanding of involuntary exit.

\footnotetext{
${ }^{23}$ Cummins et al. (1995, 1999); Grace et al. (1998); Pottier and Sommer (2002).
} 
However, while the data were available for insolvent firms, an insufficient level of detailed data (e.g., governance, internal controls, risk transfer, etc.) for solvent companies limited the capacity to also conduct regression analysis using firm-level data. The relatively few Canadian involuntary exits (35), and fewer still with detailed and consistently measured financial data, limit the feasibility of regression analysis, although this could be an avenue of further study if a sufficient data set could be developed. While the macroeconomic relationships were found to hold in the multivariate analysis (and are briefly described in the discussion section), the need for more data and observations limits this form of analysis.

As in $\mathrm{McDonnell}^{24}$ and the $\mathrm{EU},{ }^{25}$ a detailed analysis of the governance, corporate strategic decisions/priorities, internal processes (data, technology, accounting and reporting, internal control procedures, product distribution, claims handling), risk decisions (underwriting, investment, reinsurance), resource flows (premiums, claims, expenses, reinsurance, investments, non-claim liabilities) and financial outcomes was conducted. The analysis generated a risk map for each insolvent institution. The process of mapping and analyzing the data using a set of decision rules allowed us to develop a broader understanding of why a particular institution was wound-up. The primary areas of analysis are included in the risk map adapted from these sources (Figure 2).

As an example of part of the process, in the case of governance, we would look at management and the Board of Directors and consider the number of years of experience in the industry and relevant lines of business by management: whether there were conflicts of interest (in outsourcing arrangements, etc.), controls on cash management and whether there were sufficient information systems in place to monitor claims trends and other business activities. Alleged fraud was said to occur only if charges were actually laid.

As another example, in the case of reinsurance, we investigated the extent of actual risk transfer, reliance of the institution on reinsurance, role of reinsurance commissions and whom the treaty was with. We followed the network of treaties and risk-transfer agreements between related institutions and third parties to identify the extent of risk transfer. Looking at a single specific arrangement could be misleading as it could appear that the institution had transferred risk to a reinsurer. However, in some cases the network of agreements meant that little, if any, actual risk transfer had occurred. In such cases this would have been virtually impossible to discern from the publicly available financial statements (and sometimes even difficult for supervisory authorities with their access to private data). Once all these considerations were identified, what needed to be clarified is what role and if any, reinsurance played in the eventual insolvency of the institution.

The extent to which such factors were identified as playing a part in the insolvency and given the level and quality of data among insolvencies - meant that some considerations were pursued into greater detail than others. Reasonability checks on the considerations and causes of insolvency were conducted with liquidators and supervisory authorities.

\footnotetext{
${ }^{24}$ McDonnell (2002).

${ }^{25}$ EU (2002).
} 


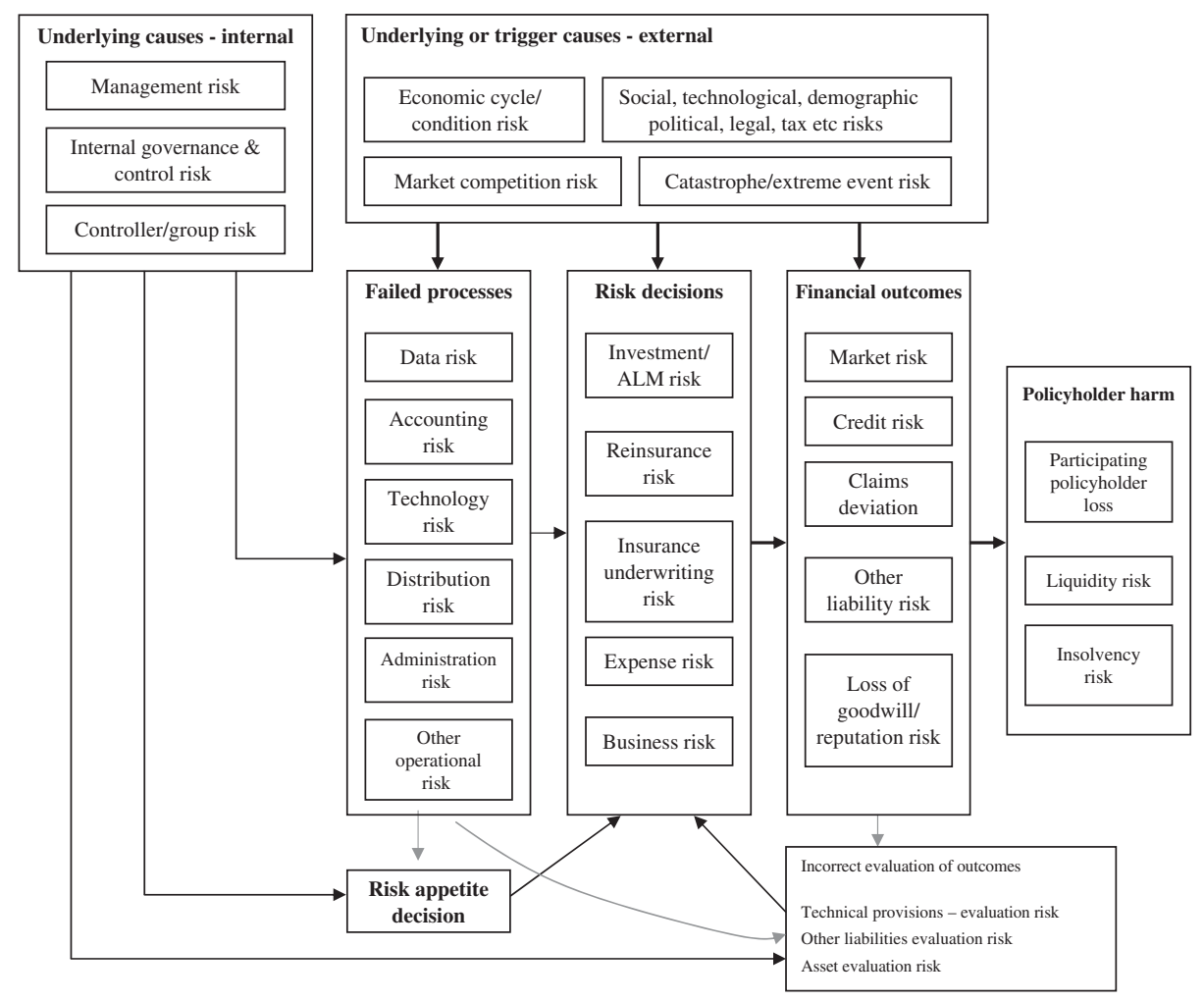

Figure 2. Risk map framework.

In addition to qualitative factors, financial data for 10 years (where available) prior to the winding-up was used for all insurance companies in the sample. Risks and behavior were inferred by analyzing data on premium growth, capital levels, assets and liabilities, liquidity, investment performance and dependence on reinsurance arrangements. At the end, a detailed risk map was constructed for each insurer mapping out the various risks and interactions between those risks and the ultimate financial outcomes.

Insurance companies generally fail as the result of the interaction of a number of factors. The primary or proximate cause for the purposes of this study is defined as the factor or trigger that led to a winding-up order being issued. In most cases, the proximate cause was merely the final challenge following a set of other contributing causes that led to the insurer's failure.

\section{Data}

The main sources of financial information utilized in this study were from MSA Research, Insurance T.R.A.C. Report (Canada), Canadian Insurance Statistical Issue, Canadian Underwriter Statistical Issue, General Insurance Register, OSFI's Annual Reports, the Property and Casualty Insurance Compensation Corporation (PACICC) files on its liquidations and A.M. Best. For the early impairments (prior to 1979), the 
data lack detail and in some cases were not available. For companies showing signs of impairment after 1979 and especially after 1990, the data were available and highly detailed.

The qualitative data were gathered from court documentation, liquidator reports and other confidential reports available to PACICC as the industry guarantee fund responsible for paying the claims of insolvent property and casualty insurers.

This study, which is the most comprehensive insolvency study in the Canadian industry, covers financial impairments for the entire P\&C insurance industry in Canada. Since insurers voluntarily file their financial data with many of the data sources, some data may not have been available. Data for provincial companies were provided from provincial superintendents annual reports. In some cases financial data from these sources were supplemented by data from the liquidation. It is imperative to point out that this study does not include the "near misses" that are defined as companies that would have wound up if they had not been merged or acquired by another insurer.

\section{Insolvency and company characteristics}

External factors such as catastrophes, volatile interest rates or financial markets may contribute to an involuntary exit of an insurance company but in our sample they are never the exclusive cause of an involuntary exit. Profitability, whether measured by return on equity (ROE) or a loss metric such as the combined ratio has not surprisingly been consistently found to be linked to insolvency. ${ }^{26}$

Effectively, every insurance company in the market (geographic or product) is exposed to catastrophes, volatility in interest rates or changes in equity prices. Therefore, the key question is, what characteristics distinguish companies that exit involuntarily from those that survive? We identified four characteristics that played a role in most Canadian insolvencies:

- governance and internal controls;

- new entrants;

- growth;

- firm size.

\footnotetext{
${ }^{26}$ With only 35 involuntary exits over the past half century and only 15 since 1990 (when data become more detailed), there are too few observations for meaningful statistical analysis. Nevertheless to get a sense as to whether the results might be consistent with other studies, we did regress the involuntary exit rate on macroeconomic variables such as profitability (ROE and combined ratio) and financial markets (interest rate volatility as defined by the annual standard deviation of 3-year government of Canada bonds and changes in the Toronto Stock Exchange Composite index). Interest rate volatility and profitability robustly had $p$-values below 5 percent in the post-1990 period under a number of specifications (with an $R^{2}$ around 0.55 ). However, using the data over a longer 32-year sample does not provide any macroeconomic variables that are significant. The change in accounting and actuarial standards and in the regulatory model in the late 1980s to one of more rigorous monitoring and early intervention from one of preventing insolvency may be a contributing factor. Adding a dummy variable for these changes makes the profitability variable significant at the 10 percent level of confidence but the $R^{2}$ remains small (11-15 percent range).
} 


\section{Governance and internal controls}

Both A.M. Best ${ }^{27}$ and McDonnell, ${ }^{28}$ in their studies of U.S. and European insurance company involuntary exits, found that management and governance issues appeared to lead to decisions or failed processes that caused companies to fail. Further, a number of studies suggest that management styles and internal processes persist strongly over time. ${ }^{29}$ Risks that are persistently poorly managed create an environment where an insurance company is more vulnerable to adverse external events. The A.M. Best ${ }^{30}$ and McDonnell ${ }^{31}$ findings are largely consistent with the firm survival research that links quality of management with firm survival. For the majority of the insolvencies in Canada (61 percent), the cause of involuntary exit can ultimately be traced to a strategic risk decision by management.

Internal controls and financial reporting are an important aspect for the accountability and operational efficiency of an insurance company. Internal controls and processes may break down for a number of reasons, but company solvency risk is further increased when they are purposefully circumvented. In 10 cases, internal controls - defined as a failure in oversight processes - were identified as being weak or non-existent. Alleged fraud was involved in an additional three ( 9 percent) of the identified involuntary exits in the entire period covered in the study (1960-2005). It was also identified as a contributing factor to other insolvencies. Most of these failed companies were newly licensed and operating for less than 3 years.

\section{New entrants}

The research literature has consistently shown that the likelihood of firm survival tends to increase with the age of the firm. While the literature is largely confined to the manufacturing industry, this finding holds across different sectors, time periods and even countries. ${ }^{32}$ As can be seen from Figures 3 and 4, the age distribution of insolvent insurance companies is consistent with this literature. The literature generally notes that new entrants face strong competition from companies already entrenched in the market and may have inexperienced management teams.

Nearly one-third (29.4 percent) of Canadian P\&C insurance companies that entered the market since 1980 exited involuntarily. The average age of these failed companies at the time of insolvency was 7.9 years.

Analysis of the age distribution of 164 involuntarily exited insurance companies incorporated since 1980 in the United States and Canada suggests that the greatest risk of insolvency for a $\mathrm{P} \& \mathrm{C}$ insurance company is during the first 6 years after start up. From the sample of involuntarily exiting insurers, 39 percent failed within the first 5 years, and 69.5 percent failed within the first 10 years of operation.

\footnotetext{
${ }^{27}$ A.M. Best (2004).

28 McDonnell (2002).

${ }^{29}$ Nelson and Winter (1982); Nelson (1991); Dosi et al. (2000).

${ }^{30}$ A.M. Best (2004).

${ }^{31}$ McDonnell (2002).

${ }^{32}$ Thompson (2005); Dunne et al. (1988).
} 


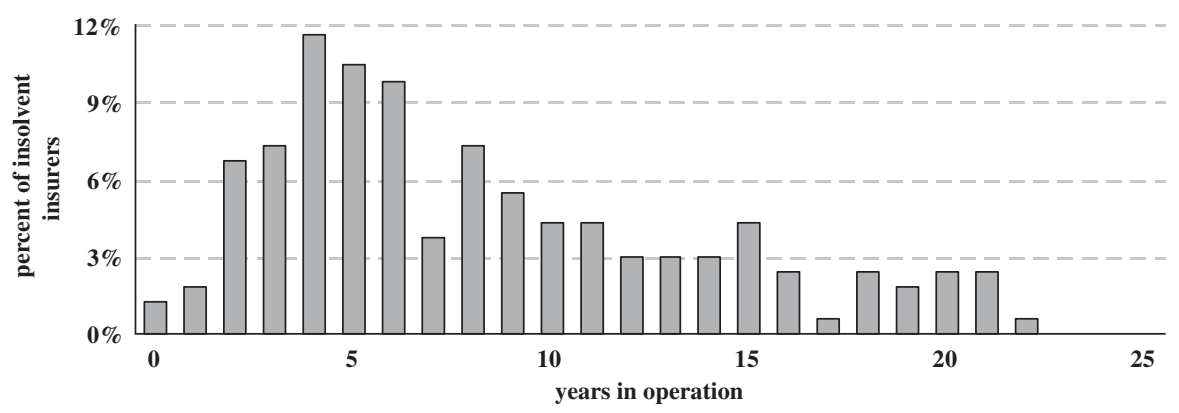

Figure 3. Age distribution of insolvent insurance companies (Canada and U.S. incorporated since 1980). Source: PACICC, with data from state department of insurance, A.M. Best.

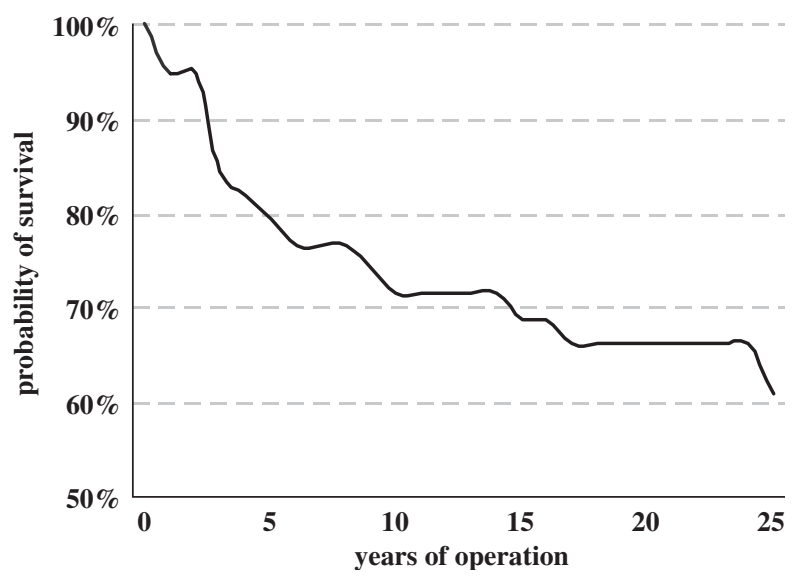

Figure 4. New P\&C insurance company survival rates (involuntary exits-Canada). Source: PACICC, with data from provincial and federal superintendents of insurance.

Using data on involuntary exits and new entrants obtained from the annual reports of provincial and federal insurance Superintendents, we estimated the survival probability using the Kaplan-Meier method for P\&C insurers. ${ }^{33}$ As shown in Figure 4, survival probability for new entrants levels off after 10-15 years of operation.

\section{Growth}

Rapid growth - defined for companies with more than 2 years of operation as being growth that is more than twice the industry average in the 2 years preceding the

${ }^{33}$ This is a conditional probability (the probability of being a survivor (not insolvent) at the end of the interval on condition that the insurer was a survivor at the beginning of the interval). Survival to any time point is calculated as the product of the conditional probabilities of surviving each time interval. Firms that exit in a solvent fashion are considered survivors. 
wind-up order - is the third leading cause of involuntary exit in Canada and was involved in six (18 percent) of the identified involuntary exits. On average, these insurers grew by more than five times that of the industry. Rapid growth was identified as a contributing factor to exit for 23 percent of the failed companies. Excluding companies that exited the market as the result of the failure of a foreign parent, twothirds of insurers exhibited rapid growth in some or all lines of business that they wrote, prior to exiting the market involuntarily.

In many cases failing companies tended to grow rapidly in the last few years of business. The population of involuntarily exiting companies, where rapid growth was not identified as either a proximate or contributing cause (about one-third of the population), grew rapidly, on average, for 1.6 years prior to being wound-up. The subgroup of companies, where rapid growth was identified as either a main or a contributing factor, on average, grew rapidly for 2 years prior to being wound-up. Commonly, these insurers were using incoming premium revenue to pay claims. In these periods prior to wind-up, financial ratios began to deviate from previous company and industry patterns.

For an insurance company, rapid growth is usually accompanied by deteriorating loss reserves and was the most frequent contributing cause (67 percent) for companies of involuntary exit. Furthermore, two-thirds of the companies with rapid growth as their main cause had deficient loss reserves contribute to involuntary exit.

The incentive to embark on long-term, aggressive expansion strategies tends to increase during periods associated with diminishing capital strength. Companies may also enter new areas of business where they lack expertise. Moreover, during periods of rising short-term interest rates, some insurers may grow rapidly in the hope that investment income from the increased premium writings will offset underwriting losses.

\section{Firm size}

Involuntary exits in Canada have typically been small insurers writing significantly less than 1 percent of total industry premium. In the firm survival literature, a key empirical regularity is that survival is highly dependent on firm size and age. ${ }^{34}$ The literature exploring these relationships has found that age and firm size are positively correlated, suggesting that firm size is largely a proxy for age. ${ }^{35}$

Cummins and Phillips ${ }^{36}$ estimated the risk premium associated with P\&C insurers and found evidence that larger insurers are less sensitive to financial distress than smaller insurers. This is the expected result if larger firms are also more diversified and have better access to capital. However, the impact of the size factor was much smaller than other risk factors. Further, the firm size betas estimated by the authors were smaller for $\mathrm{P} \& \mathrm{C}$ insurers than for firms in other industries, suggesting that the size effect is less pronounced in the P\&C industry than for other industries.

\footnotetext{
34 Thompson (2005); Dunne et al. (1988).

35 Thompson (2005).

${ }^{36}$ Cummins and Phillips (2005).
} 
While some larger and older insurers do exit the market involuntarily, the risk of exit in Canada appears to be substantially higher for newer and smaller insurance companies.

\section{Causes of insolvency}

Figure 5a identifies the primary or proximate causes of involuntary exit for the 35 Canadian insurance companies that were wound up between 1960 and 2005. However, as we have noted previously there is rarely a single cause of involuntary exit. Insurance company failures are generally caused by multiple factors. The primary or proximate cause is defined as the factor that led to a winding-up order being issued. In most cases, the proximate cause was merely the final challenge following a set of other contributing causes that led to the insurer's failure.

Figure 5b identifies the primary causes for insurer involuntary exit since 1995 . The reason for segmenting at 1995 is based on significant changes in corporate governance, and the introduction of early warning tests such as MAT (Minimum Asset Test) that occurred around that time.

Prior to 1995, deficient loss reserves were identified as the leading cause of involuntary exits, accounting for nearly one-third of such exits. The failure of a foreign parent (home office) accounted for one-quarter of the involuntary exits experienced by the industry. Rapid growth and alleged fraud together accounted for another quarter of all involuntary exits. Fourth on the list of main causes pre-1995 is overstated assets, accounting for 8 percent of involuntary exits.

Since 1960, and similar to A.M. Best's findings, inadequate pricing and deficient loss reserves are an important cause of insurer involuntary exit in Canada. This is not surprising as the adequate pricing of risk and reserving for future claims is the core function of an insurance company and getting it wrong would be expected to have important implications. In an analytical framework this means that the premiums collected should match expected losses. In this framework, assuming that insurers are rational decision makers in that they utilize all available information in their pricing
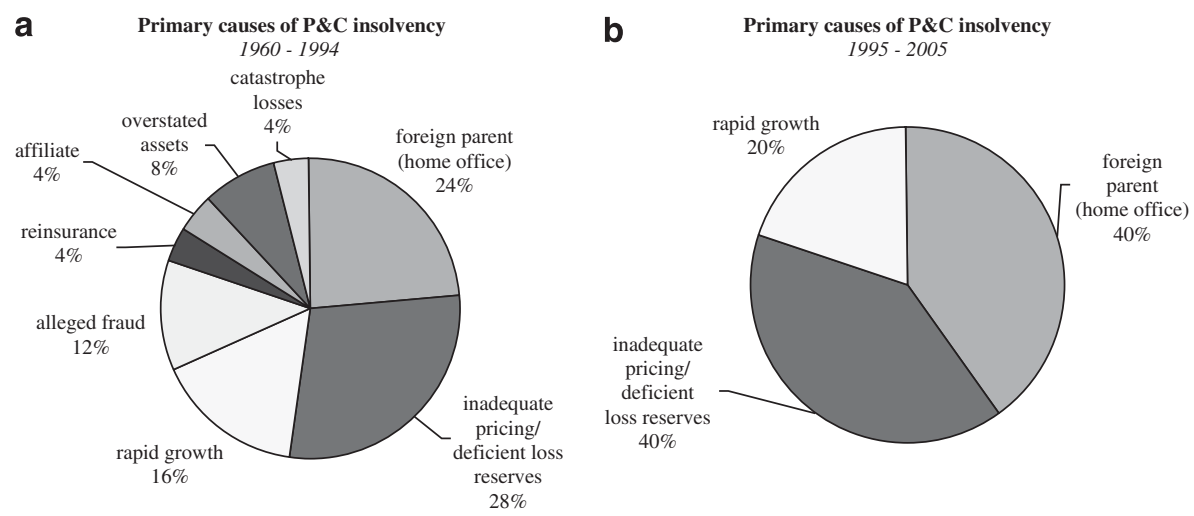

Figure 5. (a) Primary causes of $P \& C$ insolvency 1960-1994. (b) Primary causes of P\&C insolvency 19952005. Source: Authors. 
decisions, then an insurer would set prices using data that are one-period old. ${ }^{37}$ The following function describes the pricing of insurance:

$$
P_{t}=E\left(L_{t-1}\right)+E\left(\Pi_{t}^{u}\right)
$$

where $E\left(L_{t-1}\right)$ is the expected loss (claims) experience, $\Pi_{t}^{u}$ is the expected underwriting result (profit/loss). In a competitive market, without a systemic error, which introduces mispricing throughout the system, we would expect this function to hold. ${ }^{38}$ Insurance premiums earned in period $t$ are set aside as reserves to pay claims from period $t$ (which may be fully realized in later periods such as $t+1$ ). In subsequent periods as claims become realized, if insufficient reserves were set aside, an insurer must deplete capital - the margin between solvency and insolvency - to increase reserves. A company with insufficient capital must use current revenues to support current claims and a portion of past claims. Persistent and consistent underpricing and inadequate reserving may ultimately lead to insolvency. Every insurer identified as failing due to under-reserving failed when the underwriting cycle worsened and the industry entered a period of low profitability.

Among Canadian insurers who got their pricing wrong, nearly half (47.4 percent) were either new companies or entering into entirely new or non-core lines of business. Several insurers were also subject to large unexpected increases in liability claims that were not priced into the product with adequate reserves established. Also, several insurers in run-off, which may have entered into run-off due to low profitability, initially were also eventually found to have price misestimation and inadequate reserves and ultimately were wound-up.

When combined with rapid growth, which is often future deficient loss reserves, inadequate pricing and deficient loss reserves account for nearly half of all insolvencies prior to 1995 and more than half (55 percent) following 1995. A.M. Best notes that insurers that embark on aggressive expansion strategies, particularly in new lines of business, typically experience deterioration in loss reserves and diminished capital.

Reinsurance is identified as a cause of impairment when a company's reinsurer is unable to fulfill its obligations to the insurer. Although reinsurance was found to be a main cause of insolvency only for one insurer, it was a contributing factor for 26 percent of the involuntary exit population during the period of 1960-2005.

\section{International comparison of causes of insolvency}

Several studies have been undertaken to identify the primary causes of involuntary exit in different jurisdictions. Table 1 summarizes key conclusions and information pertaining to these studies.

${ }^{37}$ When there is some uncertainty in the losses (e.g., losses in period $t-1$ are not an accurate predictor of losses today, i.e. uncertainty in the data), a stochastic error term is included in the simple model.

${ }^{38}$ Cummins and Outreville (1987) outline a simple model for insurance pricing that demonstrates this. Note that the result does not hold when there is systemic error. Mispricing could occur where there is incorrect or lagged information on loss costs. Some accounting conventions, rate regulation or inappropriate estimation techniques could introduce systemic mispricing. 
The Geneva Papers on Risk and Insurance - Issues and Practice

480

Table $1^{\mathbf{a}}$ International comparison of causes of insolvency

\begin{tabular}{|c|c|c|c|c|}
\hline Jurisdictions & United States & Canada & $E U$ & Asia $^{\mathrm{b}}$ \\
\hline \multicolumn{5}{|c|}{ Leading cause of insolvency } \\
\hline 1. & $\begin{array}{l}\text { Inadequate pricing/ } \\
\text { deficient loss } \\
\text { reserves }\end{array}$ & $\begin{array}{l}\text { Inadequate pricing/ } \\
\text { deficient loss } \\
\text { reserves }\end{array}$ & $\begin{array}{l}\text { Inadequate pricing/ } \\
\text { deficient loss } \\
\text { reserves }\end{array}$ & $\begin{array}{l}\text { Inadequate pricing/ } \\
\text { deficient loss } \\
\text { reserves }\end{array}$ \\
\hline 2. & Fraud & $\begin{array}{l}\text { Foreign parent } \\
\text { (home office) }\end{array}$ & Asset risk & Asset risk \\
\hline 3. & $\begin{array}{l}\text { Significant change of } \\
\text { business }\end{array}$ & Rapid growth & Failed systems & Concentration/bus. \\
\hline Methodology & Survey & Survey & Survey & Regression \\
\hline $\begin{array}{l}\text { \# of } \\
\text { companies }\end{array}$ & 871 & 35 & 140 & 159 \\
\hline Source & A.M. Best (2004) & This study & FSA (2002) & $\begin{array}{l}\text { Chen and Wong } \\
\text { (2004) }\end{array}$ \\
\hline
\end{tabular}

${ }^{a}$ While useful, such comparisons should be used with caution as definitions and decision trees may differ.

${ }^{\mathrm{b}}$ Countries included in this study are Japan, Singapore, Malaysia and Taiwan.

Except for the study concerning Asia, all the studies surveyed impaired P\&C insurance companies. The study by Chen and Wong (Asian study) ${ }^{39}$ uses a logit regression analysis instead to identify the main factors that impact an insurer's financial health.

Table 1 shows that inadequate pricing and deficient loss reserves are the leading cause of involuntary exit in all jurisdictions. Deficient loss reserves accounted for 54 percent of $\mathrm{P} \& \mathrm{C}$ insurance failures in the United States, 33 percent for Canada and 36 percent for EU countries. The study by Chen and Wong found that inadequate pricing and deficient loss reserves had a significant negative impact on insurer profitability.

Unlike the other jurisdictions, the failure of a foreign parent (home office) was found to be one of the top three leading causes of involuntary exit in Canada. The studies of both EU and Asia identified asset risk as a leading cause of impairment. In these cases, insurers were not appropriately considering the correlation between the risk profiles of their assets and liabilities. The cross-national comparison highlights the importance of adequate pricing and appropriate reserving in the $\mathrm{P} \& \mathrm{C}$ insurance industry.

\section{Discussion}

During the period between 2000 and 2005, insurers in the United States and United Kingdom were assessed USD \$5.7 billion (CDN \$7.1 billion) and £630.6 million (CDN $\$ 774$ million), respectively. ${ }^{40} \mathrm{~A}$ record number of Canadian insurers were also

\footnotetext{
${ }^{39}$ Chen and Wong (2004).

${ }^{40}$ This includes both actual invoices sent to insurers and the recoveries from past liquidations that were used for current liquidation instead of being returned to insurance companies.
} 
Table 2 Proximate causes of involuntary exit in Canada (1960-2005)

\begin{tabular}{lr}
\hline Inadequate pricing/deficient loss reserves (DLR) & $31 \%$ \\
Foreign parent/home office (other) & $20 \%$ \\
Rapid growth & $17 \%$ \\
Foreign parent/home office (DLR) & $9 \%$ \\
Alleged fraud & $9 \%$ \\
Overstated assets & $6 \%$ \\
Reinsurance & $3 \%$ \\
Canadian affiliate & $3 \%$ \\
Catastrophe losses & $3 \%$ \\
\hline
\end{tabular}

Table 3 Contributing causes of involuntary exit in Canada (1960-2005) ${ }^{\mathrm{a}}$

\begin{tabular}{lr}
\hline Inadequate pricing/deficient loss reserves & $77 \%$ \\
Rapid growth & $43 \%$ \\
Foreign parent/home office & $32 \%$ \\
Reinsurance & $29 \%$ \\
Overstated assets & $15 \%$ \\
Alleged fraud & $12 \%$ \\
Canadian affiliate & $9 \%$
\end{tabular}

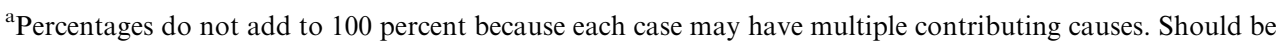
read as percent of total involuntary exits that occurred experienced the factor.

vulnerable over this period with six companies being wound-up with an assessment liability of $\mathrm{CDN} \$ 87.5$ million. In a competitive $\mathrm{P} \& \mathrm{C}$ insurance industry, it is inevitable that some insurers will encounter financial difficulties and in exceptional circumstances some will become insolvent.

As it is human nature to look for "the cause", it therefore bears repeating that there is rarely a single cause of involuntary exit. Rather, insurance company failures are generally the result of multiple factors. Table 2 summarizes the proximate causes of involuntary exit identified for the 35 involuntary exits reviewed.

In most cases, the proximate cause was merely the final challenge following a set of other contributing causes that led to the insurer's failure. Table 3 presents a summary of the contributing causes of involuntary exit.

While none of the factors are surprising in their appearance among the causes of insolvency, they do highlight two things. First, other than inadequate reserving and pricing, when compared with other jurisdictions, the causes of insolvency are not in the same order of frequency across jurisdictions, suggesting that cookie cutter approaches to understanding and applying insolvency research from different jurisdictions may not always be appropriate. Second, while supervisory authorities have traditionally focused on asset risks, liability-related risks and the stability of foreign parents have historically mattered more for Canadian solvency.

The high-level analysis presented in this report and observations drawn from risk maps of individual insolvencies offer a number of specific lessons and observations. These observations are outlined and grouped into relevant categories and presented below. 


\section{Governance/management}

Whether it was inexperience, underwriting misjudgement, capital management decisions or fraud, in the end strategic choices and risk appetites were at the root of all causes of insolvency. From the Canadian experience with insolvency, the following observations can be made:

- experience matters, and greater experience of senior management reduces the incidence of insolvency;

- strong internal controls and financial reporting reduce insolvency risk, as 35 percent of involuntary exits demonstrated clear breakdowns in internal controls;

- up to 2 years prior to the wind-up of a company, management in many cases undertook strategies that could be described as "gambling for survival".

While there are too few observations for any conclusions on whether market discipline is effective, we nevertheless observe that every involuntary exit identified with internal control deficiencies was domiciled in provincial jurisdictions with limited (e.g., premiums written) or no public disclosure of financial information.

\section{Operational risk}

In the Canadian experience, insurers that involuntarily exited often had a substantial concentration of risk or initiated sudden changes in the business they underwrote. Risk concentration may occur in the form of geographic and/or product concentration. While diversification does not prevent involuntary exit, there appears to be some evidence that it does increase the survival rate of companies. Further, when expanding into new lines, sticking to related lines reduces the risk of exit. Several involuntary exits were in the process of reinventing themselves and expanding into new lines of business in which the company had limited experience.

\section{Underwriting}

At the macro level, insurer involuntary exit was found to be related to industry profitability and the underwriting cycle. During the period 1975-2005, insolvency (involuntary exits after excluding liquidity risks) occurred disproportionately in years where ROE was less than 10 percent. Over the period, insolvency was 3.2 times more likely to occur when industry ROE was below 10 percent than when it was higher. ${ }^{41}$

The relationship between profitability and insolvency appears to have become more evident in Canada since 1990. Since then, insurance company insolvency has been limited to years of poor profitability. Unfortunately there is insufficient data to test whether there was a structural change in the environment as a result of the

\footnotetext{
${ }^{41}$ Historically, the number of insolvencies declines by half with an industry ROE (lagged by 1 year) of 12 percent and does not decline again until industry ROE (lagged 1 year) exceeds 15 percent.
} 
introduction of rate regulation, reforms in financial reporting, governance and capital requirements implemented since 1990 , or whether the result is coincidental. ${ }^{42}$

Among insurer-specific factors, the leading cause of involuntary exit in Canada is inadequate pricing and deficient loss reserves, accounting for 31 percent of the impairments. This is consistent with international experience. In addition, sudden rapid growth was evident (67 percent) for a majority of failed companies (even if it did not directly contribute to the involuntary exit) and was particularly prevalent for companies where deficient loss reserves were a proximate cause of involuntary exit. In general, sudden growth in unpaid claims liabilities was the primary driver of involuntary exit. In 77 percent of involuntary exits, the failed insurer experienced sudden growth in unpaid claims liabilities. In the majority (88.9 percent) of cases where asset risk (reinsurance, overstated assets) was a contributing factor, this was triggered by liability-related problems (e.g., the insurer could no longer afford or was unable to get reinsurance because of its liability risk).

It should be noted that there is great diversity among companies in terms of solvency in any environment, but underwriting profitability is an important predictor of insolvency. In this context, the following observations can be made:

- adequate pricing and accurate loss reserve estimation are critical for reducing the likelihood of involuntary exit;

- rapid growth may be associated with under-pricing.

\section{Capital}

A number of complex theoretical models of firm performance offer insight into factors that influence entry into and exit from an industry. In particular, they suggest that risk-based supervision should reduce solvency risk. To date, the limited data available from the adoption of a risk-based framework for federally regulated insurers seem to support this.

Reinsurance was not a major source of insolvency but it was a contributing factor in 26 percent of failures. Reinsurance allows insurers to transfer risks that exceed their underwriting capacity or share risks that they choose not to bear alone. The purchase of reinsurance may reduce the volatility of insurer underwriting results, provide capital relief and provide specific expertise and services for an insurer. Acting as a risk transfer mechanism for large losses, reinsurance has been an important part of the insurance industry for nearly 160 years, contributing directly to the stability of the Canadian insurance markets.

However, reinsurance assets are risky in that they can deteriorate quickly, cannot be readily sold and must be actively managed. In the majority of cases the issue appears to have been one of reinsurance management by the failed insurer, rather than reinsurance failure. In some cases there were complex inter-group arrangements, in

\footnotetext{
${ }^{42}$ There were $10 \mathrm{P} \& \mathrm{C}$ insurance insolvencies (excluding liquidity risks) in Canada after 1990 and when involuntary exits resulting from fraud, catastrophe loss or reinsurance failure are removed, the pre-1990 period looks much more like that after 1990, where insolvency was 5.6 times more likely to occur in years of poor profitability.
} 
others there was over-reliance on reinsurance assets that became more difficult to obtain when the reinsurance market hardened. None of the cases involved the insolvency of a non-affiliated reinsurance company.

Analysis of the Canadian insolvency experience has identified the following general observations:

- in most cases, capital deteriorated rapidly in the final year of operation;

- supervisory authorities need to understand the risk transfer arrangements;

- in Canada, as contributors to insolvency risk, liability risks have historically been far more important than asset risks.

\section{Macro-economic environment}

Volatility in financial markets, specifically in interest rates, also had modest solvency implications. The interest rate volatility in the early 1980s and mid-1990s (in combination with the insurance cycle) appears to have contributed to the relatively high rates of insurer involuntary exit during those periods. Catastrophe losses were not found to be a source of involuntary exit in Canada, with severe weather contributing to the failure of a single regionally concentrated agricultural insurer. This result may be more fortuitous than real, as large catastrophe losses have occurred in years of strong profitability. Since catastrophe losses do not time themselves to the insurance cycle, it is possible that they may be linked to involuntary exit in the future.

Among the three waves of Canadian insurer involuntary exit, the insurance cycle and interest rate volatility were identified as catalysts for involuntary exit (Table 4).

The periods with the greatest frequency and severity of Canadian insurer involuntary exit involved more than one catalyst. When interest rate volatility and the insurance cycle did not coincide, the estimated frequency and severity of involuntary exit was substantially reduced.

\section{Monitoring and supervision}

Many of the causes of involuntary exit - particularly governance and operational risks - identified in Canada would not be found through analysis of financial indicators. This highlights the importance of using a broad-based enterprise risk management approach to solvency supervision. Our review of the Canadian insolvency experience has identified a number of general observations relevant to solvency supervision:

- financial risk ratios generally begin to fluctuate up to 2 years prior to involuntary exit and winding-up (note: because financial risk ratios also fluctuate for companies

\begin{tabular}{ll}
\hline Period of involuntary exit & Catalyst \\
\hline $1980-1985$ & Insurance cycle, interest rate volatility \\
$1991-1995$ & Insurance cycle, interest rate volatility \\
$2000-2002$ & Insurance cycle \\
\hline
\end{tabular}


that do not become insolvent, supervisors need the capacity to properly identify and monitor solvency risk);

- no single indicator, in itself, is a reliable predictor of insolvency;

- start-up companies are at greater risk of insolvency;

- supervisors need to have a good understanding of reinsurance arrangements;

- companies writing in new lines of business, outside of their area of expertise, are at greater risk;

- public data availability increases market discipline and helps identify areas of potential concern, placing pressure on companies to address problems earlier.

\section{Summary}

We conducted 35 case studies of Canadian insurance companies who involuntarily exited the market. We find that $\mathrm{P} \& \mathrm{C}$ insurance companies become insolvent for a variety of reasons that are largely non-surprising to experienced observers. Nevertheless, we note that these non-surprising sources of insolvency continue to retain the capacity to surprise. For a topical but currently non-insurance example, witness the recent subprime crisis. This issue is reminiscent of historical financial crises that involved straying away from fundamentals. Old things are often repackaged and seen as new things. For solvency supervisors and guarantee funds, understanding and being reminded of the core causes of insurer insolvency - particularly where there is staff turnover or retirement - can help mitigate this.

Overall we find that the operating environment generally provides the catalyst for insolvency, either through turbulent financial markets or reduced profitability in the industry, but most causes of involuntary exit can however be linked back to three sources: the quality of governance/management, internal operational processes and risk appetite.

While highly useful and an important part of the supervisory toolbox, there is no single indicator or set of indicators that are consistently strong predictors of insolvency. Therefore, supervisory authorities and policyholder protection systems that focus solely on financial outcomes are likely going to receive an early warning later than they might have.

From the few studies in various jurisdictions, there also appear to be few universal causes of involuntary exit across jurisdictions and hence no cookie-cutter solutions or supervisory approaches. Nevertheless supervisory authorities and policyholder protection funds can take stock of the causes of insolvency in their jurisdiction and learn from other jurisdictions (and offer lessons as well) while at the same time taking into account their own environment.

\section{References}

Barniv, R. and Hathorn, J. (1997) 'The merger of insolvency alternative in the insurance industry', Journal of Risk and Insurance 64: 89-113.

Best, A.M. (2004) Best's Insolvency Study/Property Casualty U.S. Insurers 1969-2002, Oldwick, NJ: A.M. Best Company. 
Carroll, G.R., Bigelow, L.S., Seidel M.D., L. and Tsai, L.B. (1996) 'The fates of De Novo and De Alio producers in the American Automobile Industry 1885-1981', Strategic Management Journal 17: 117-137.

Chen, R. and Wong, A.K. (2004) 'The determinants of financial health of Asian insurance companies', Journal of Risk and Insurance 71: 469-499.

Cummins, D.J., Grace, M.F. and Phillips, R.D. (1999) 'Regulatory solvency prediction in property-liability insurance: Risk-based capital, audit ratios and cash flow simulation', Journal of Risk and Insurance 66: 417-458.

Cummins, D.J., Harrington, S.E. and Klein, R.W. (1995) 'Insolvency experience, risk-based capital, and prompt corrective action in property-liability insurance', Journal of Banking and Finance 19: 511-527.

Cummins, J.D. and Outreville, J.F. (1987) 'An international analysis of underwriting cycles in propertyliability insurance', Journal of Risk and Insurance 54: 246-262.

Cummins, D.J. and Phillips, R.D. (2005) 'Estimating the cost of equity capital for property-liability insurers', Journal of Risk \& Insurance 72: 441-478.

Dosi, G., Nelson, R.R. and Winter, S.G. (2000) 'Introduction: The nature and dynamics of organizational capabilities', in G. Dosi, R.R. Nelson and S.G. Winter (eds) The Nature and Dynamics of Organizational Capabilities, New York: Oxford University Press.

Dunne, T., Roberts, M.J. and Samuelson, L. (1988) 'Patterns of firm entry and exit in U.S. manufacturing industries', RAND Journal of Economics 19: 495-515.

Eisenhardt, K.M. and Schoonhoven, C.B. (1990) 'Organizational growth: Linking founding team, strategy, environment, and growth among U.S. semiconductor ventures, 1978-1988', Administrative Science Quarterly 35: 504-529.

European Union (2002) Report: Prudential Supervision of Insurance Undertakings, Conference of Insurance Supervisory Services of Member States of the European Union, Paris (December).

Grace, M.F., Harrington, S.E. and Klein, R.W. (1998) 'Risk-based capital and solvency screening in property-liability insurance: Hypotheses and empirical tests', Journal of Risk and Insurance 65: 213-243.

Hopenhayn, H.A. (1992) 'Entry, exit, and firm dynamics in long run equilibrium', Econometrica 60: $1127-1150$.

Jovanovic, B. (1982) 'Selection and the evolution of industry', Econometrica 50: 649-670.

Klepper, S. and Simons, K.L. (2000) 'Dominance by birthright: Entry of prior radio producers and competitive ramifications in the US television receiver industry', Strategic Management Journal 21: 9971016.

Klepper, S. and Sleeper, S.D. (2001) Entry by Spinoffs, mimeo, Carnegie Mellon University, Pittsburgh.

Klepper, S. and Thompson, P. (2002) Submarkets and the Evolution of Industry, mimeo, Carnegie Mellon University, Pittsburgh.

Lee, H.S. and Urrutia, L.J. (1996) 'Analysis and prediction of insolvency in the property-liability insurance industry: A comparison of logit and hazard models', Journal of Risk and Insurance 63: 121-130.

McDonnell, W. (2002) Managing risk: Practical lessons from recent "failures" of EU insurers, Financial Services Authority Occasional Paper Series 20, London, FSA.

Mitchell, W. (1991) 'Dual clocks: Entry order influences on incumbent and newcomer market share and survival when specialized assets retain their value', Strategic Management Journal 12: 85-10.

Nelson, R.R. (1991) 'Why do firms differ and how does it matter?', Strategic Management Journal 12: 61-74.

Nelson, R.R. and Winter, S.G. (1982) An Evolutionary Theory of Economic Change, Cambridge, MA: Harvard University Press.

Pottier, S.W. and Sommer, D.W. (2002) 'The effectiveness of public and private sector summary risk measures in predicting insurer insolvencies', Journal of Financial Services Research 21: 101-116.

Sharma, P. (chairman) (2002) Prudential Supervision of Insurance Undertakings, Report of the London Working Group on Solvency II, DT/UK/232/02/REV6, Conference of the Insurance Supervisory Services of the Member States of the European Union, Paris (December).

Thompson, P. (2005) 'Selection and firm survival: Evidence from the shipbuilding industry, 1825-1914', Review of Economics and Statistics 87: 26-36.

Walsh, S.T., Kirchhoff, B.A. and Boylan, R.L. (1996) 'Founder backgrounds and entrepreneurial success: Implications for core competence strategy applications to new ventures', in P.D. Reynolds, S. Birely, J.E. Butler, W.D. Bygrave, P. Davidson, W.B. Gartner and P.P. McDougall (eds) Frontiers of Entrepreneurship Research, Wellesley, MA: Babson College. 


\section{APPENDIX}

\section{Primary causes of insurer insolvency by year}

See Table A1.

Table A1

\begin{tabular}{|c|c|c|c|c|c|c|c|c|c|}
\hline & $\begin{array}{c}\text { I } \\
\text { Inadequate } \\
\text { pricing/ } \\
\text { deficient } \\
\text { loss } \\
\text { reserves }\end{array}$ & $\begin{array}{c}\text { II } \\
\text { Parent } \\
\text { failure }\end{array}$ & $\begin{array}{c}\text { III } \\
\text { Rapid } \\
\text { growth }\end{array}$ & $\begin{array}{c}\text { IV } \\
\text { Alleged } \\
\text { fraud }\end{array}$ & $\begin{array}{c}V \\
\text { Overstated } \\
\text { assets }\end{array}$ & $\begin{array}{c}\text { VI } \\
\text { Reinsurance }\end{array}$ & $\begin{array}{c}\text { VII } \\
\text { Catastrophe } \\
\text { losses }\end{array}$ & $\begin{array}{c}\text { VIII } \\
\text { Failure of a } \\
\text { Canadian } \\
\text { affiliate }\end{array}$ & Total \\
\hline 1960 & 0 & 0 & 0 & 0 & 0 & 0 & 0 & 0 & 0 \\
\hline 1961 & 1 & 0 & 0 & 0 & 0 & 0 & 0 & 0 & 1 \\
\hline 1962 & 0 & 0 & 0 & 0 & 0 & 0 & 0 & 0 & 0 \\
\hline 1963 & 0 & 0 & 0 & 0 & 0 & 0 & 0 & 0 & 0 \\
\hline 1964 & 0 & 0 & 0 & 0 & 0 & 0 & 0 & 0 & 0 \\
\hline 1965 & 0 & 0 & 0 & 0 & 0 & 0 & 0 & 0 & 0 \\
\hline 1966 & 0 & 0 & 2 & 0 & 0 & 0 & 0 & 0 & 2 \\
\hline 1967 & 0 & 0 & 0 & 0 & 0 & 0 & 0 & 0 & 0 \\
\hline 1968 & 0 & 0 & 0 & 0 & 0 & 0 & 0 & 0 & 0 \\
\hline 1969 & 0 & 0 & 0 & 0 & 0 & 0 & 0 & 0 & 0 \\
\hline 1970 & 0 & 0 & 0 & 0 & 0 & 0 & 0 & 0 & 0 \\
\hline 1971 & 0 & 0 & 0 & 0 & 0 & 0 & 0 & 0 & 0 \\
\hline 1972 & 0 & 0 & 0 & 0 & 0 & 0 & 0 & 0 & 0 \\
\hline 1973 & 0 & 0 & 0 & 0 & 0 & 0 & 0 & 0 & 0 \\
\hline 1974 & 0 & 0 & 0 & 0 & 0 & 0 & 0 & 0 & 0 \\
\hline 1975 & 0 & 0 & 0 & 0 & 0 & 0 & 0 & 0 & 0 \\
\hline 1976 & 0 & 0 & 0 & 0 & 0 & 0 & 0 & 0 & 0 \\
\hline 1977 & 0 & 0 & 0 & 0 & 0 & 0 & 0 & 0 & 0 \\
\hline 1978 & 0 & 0 & 0 & 0 & 0 & 0 & 0 & 0 & 0 \\
\hline 1979 & 0 & 1 & 0 & 0 & 0 & 0 & 0 & 0 & 1 \\
\hline 1980 & 0 & 0 & 0 & 0 & 0 & 0 & 0 & 0 & 0 \\
\hline 1981 & 1 & 0 & 1 & 0 & 0 & 0 & 0 & 0 & 2 \\
\hline 1982 & 0 & 0 & 0 & 0 & 1 & 0 & 0 & 0 & 1 \\
\hline 1983 & 1 & 0 & 0 & 1 & 0 & 0 & 0 & 0 & 2 \\
\hline 1984 & 0 & 0 & 0 & 0 & 0 & 0 & 1 & 0 & 1 \\
\hline 1985 & 1 & 1 & 0 & 0 & 0 & 0 & 0 & 0 & 2 \\
\hline 1986 & 0 & 1 & 0 & 0 & 0 & 1 & 0 & 0 & 2 \\
\hline 1987 & 0 & 0 & 0 & 0 & 0 & 0 & 0 & 0 & 0 \\
\hline 1988 & 0 & 0 & 0 & 0 & 0 & 0 & 0 & 0 & 0 \\
\hline 1989 & 2 & 1 & 1 & 0 & 1 & 0 & 0 & 1 & 6 \\
\hline Total & 6 & 4 & 4 & 1 & 2 & 1 & 1 & 1 & 20 \\
\hline Percent & 30.00 & 20.00 & 20.00 & 5.00 & 10.00 & 5.00 & 5.00 & 5.00 & 100.00 \\
\hline 1990 & 0 & 1 & 0 & 0 & 0 & 0 & 0 & 0 & 1 \\
\hline 1991 & 0 & 0 & 0 & 1 & 0 & 0 & 0 & 0 & 1 \\
\hline 1992 & 0 & 0 & 0 & 0 & 0 & 0 & 0 & 0 & 0 \\
\hline 1993 & 1 & 1 & 0 & 0 & 0 & 0 & 0 & 0 & 2 \\
\hline 1994 & 0 & 0 & 0 & 1 & 0 & 0 & 0 & 0 & 1 \\
\hline 1995 & 1 & 2 & 1 & 0 & 0 & 0 & 0 & 0 & 4 \\
\hline
\end{tabular}


Table A1 (continued)

\begin{tabular}{|c|c|c|c|c|c|c|c|c|c|}
\hline & $\begin{array}{c}I \\
\text { Inadequate } \\
\text { pricing/ } \\
\text { deficient } \\
\text { loss } \\
\text { reserves }\end{array}$ & $\begin{array}{c}\text { II } \\
\text { Parent } \\
\text { failure }\end{array}$ & $\begin{array}{c}\text { III } \\
\text { Rapid } \\
\text { growth }\end{array}$ & $\begin{array}{c}\text { IV } \\
\text { Alleged } \\
\text { fraud }\end{array}$ & $\begin{array}{c}V \\
\text { Overstated } \\
\text { assets }\end{array}$ & $\begin{array}{c}\text { VI } \\
\text { Reinsurance }\end{array}$ & $\begin{array}{c}\text { VII } \\
\text { Catastrophe } \\
\text { losses }\end{array}$ & $\begin{array}{c}\text { VIII } \\
\text { Failure of a } \\
\text { Canadian } \\
\text { affiliate }\end{array}$ & Total \\
\hline 1996 & 0 & 0 & 0 & 0 & 0 & 0 & 0 & 0 & 0 \\
\hline 1997 & 0 & 0 & 0 & 0 & 0 & 0 & 0 & 0 & 0 \\
\hline 1998 & 0 & 0 & 0 & 0 & 0 & 0 & 0 & 0 & 0 \\
\hline 1999 & 0 & 0 & 0 & 0 & 0 & 0 & 0 & 0 & 0 \\
\hline 2000 & 1 & 0 & 0 & 0 & 0 & 0 & 0 & 0 & 1 \\
\hline 2001 & 1 & 1 & 1 & 0 & 0 & 0 & 0 & 0 & 3 \\
\hline 2002 & 1 & 0 & 0 & 0 & 0 & 0 & 0 & 0 & 1 \\
\hline 2003 & 0 & 1 & 0 & 0 & 0 & 0 & 0 & 0 & 1 \\
\hline 2004 & 0 & 0 & 0 & 0 & 0 & 0 & 0 & 0 & 0 \\
\hline 2005 & 0 & 0 & 0 & 0 & 0 & 0 & 0 & 0 & 0 \\
\hline Total & 5 & 6 & 2 & 2 & 0 & 0 & 0 & 0 & 15 \\
\hline Percent & 33.33 & 40.00 & 13.33 & 13.33 & 0.00 & 0.00 & 0.00 & 0.00 & 100.00 \\
\hline
\end{tabular}

\section{About the Authors}

Darrell Leadbetter is the manager, Research, at the Property and Casualty Insurance Compensation Corporation (PACICC), Canada's policyholder protection fund for $\mathrm{P} \& \mathrm{C}$ insurance. $\mathrm{He}$ is responsible for the risk monitoring, analysis and solvency research program at PACICC.

Suela Dibra, prior to joining the Insurance Bureau of Canada and working in the Policy Development department's industry analysis group, was a research coordinator at PACICC. 